Abstract

\title{
Short-Term Reaction of Dionaea muscipula J. Ellis Photosynthetic Apparatus after UV-A Radiation Treatment ${ }^{\dagger}$
}

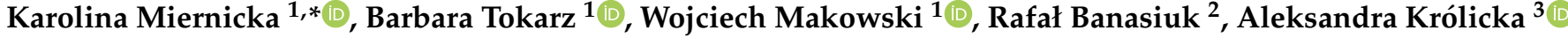 \\ and Krzysztof Michał Tokarz ${ }^{1, * \mathbb{D}}$
}

1 Department of Botany, Physiology and Plant Protection, Faculty of Biotechnology and Horticulture, University of Agriculture in Krakow, 31-425 Krakow, Poland; barbara.tokarz@urk.edu.pl (B.T.); wojtek.makowski.1305@gmail.com (W.M.)

2 Institute of Biotechnology and Molecular Medicine, 80-180 Gdansk, Poland; banasiuk@herbiopharm.pl

3 Laboratory of Biologically Active Compounds, Intercollegiate Faculty of Biotechnology UG and MUG, University of Gdansk, 80-307 Gdansk, Poland; aleksandra.krolicka@biotech.ug.edu.pl

* Correspondence: karolina.km.miernicka@gmail.com (K.M.); km.tokarz.ipbb@gmail.com (K.M.T.)

+ Presented at the 1st International Electronic Conference on Agronomy, 3-17 May 2021; Available online: https://iecag2021.sciforum.net/.

Citation: Miernicka, K.; Tokarz, B.; Makowski, W.; Banasiuk, R.; Królicka, A.; Tokarz, K.M. Short-Term Reaction of Dionaea muscipula J. Ellis

Photosynthetic Apparatus after UV-A Radiation Treatment. Biol. Life Sci. Forum 2021, 3, 43. https://doi.org/ 10.3390/IECAG2021-09743

Academic Editor: Youssef Rouphael

Published: 1 May 2021

Publisher's Note: MDPI stays neutral with regard to jurisdictional claims in published maps and institutional affiliations.

Copyright: (C) 2021 by the authors. Licensee MDPI, Basel, Switzerland. This article is an open access article distributed under the terms and conditions of the Creative Commons Attribution (CC BY) license (https:// creativecommons.org/licenses/by/ $4.0 /)$.
Abstract: Dionaea muscipula J. Ellis is a South and North Carolina carnivorous endemic plant with medicinal properties. Its natural habitat is characterized by low availability of nutrients and poor plant cover, resulting in Venus flytrap exposure to various stress factors (especially UV-A radiation). To evaluate the response of Dionaea muscipula photosynthetic apparatus to increased levels of UV-A radiation, plants cultivated in controlled conditions (30-40\% air humidity, temperature $23 \pm 1{ }^{\circ} \mathrm{C}$, light intensity $290 \mu \mathrm{mol} \mathrm{m}{ }^{-2} \mathrm{~s}^{-1}, 16 \mathrm{~h}$ light $/ 8 \mathrm{~h}$ dark) (Control) were treated additionally with $50 \mu \mathrm{mols}$ $\mathrm{m}^{-2} \mathrm{~s}^{-1} \mathrm{UV}-\mathrm{A}$ radiation for $24 \mathrm{~h}$ (Treated). Measurements of gas exchange, chlorophyll fluorescence and photosynthetic pigment content were conducted immediately after the exposure, both in the Control and Treated plants. Additionally, the same parameters were evaluated in the next 24 hours (Recovery). UV-A treatment (Treated) did not change chlorophyll $a+b$ content and chlorophyll $a / b$ ratio. Furthermore, an increased level of electron carriers (Area, Sm) and increased efficiency of electron transport between $Q_{A}$ and PSI $\left(\Phi R_{0}, \delta R_{0}, \rho R_{0}\right)$ was observed. Further, PSI and electron acceptors demonstrated an increased ability to oxidize reduced plastoquinone pool ( $\mathrm{V}_{\mathrm{I}}$ decrease). As a consequence, the rate of net photosynthesis increased significantly. After $24 \mathrm{~h}$ from the exposure (Recovery), the chlorophyll $a+b$ content declined but the ratio of chlorophyll $a / b$ did not alter, which indicates a decrease in the size of photosynthetic antennas and the number of active PSII centers. Additionally, inactivation of the reaction centers ( $F_{0}$ decrease, $V_{J}$ and $V_{I}$ increase $)$ and a decrease in the amount of electron carriers, especially PQ poll (Sm), was observed. Moreover, a decrease of electron flux and efficiency of electron transport between $\mathrm{Q}_{\mathrm{A}}$ and PSI occurred (decrease of: $\Phi \mathrm{E}_{0}$, $\left.\psi \mathrm{E}_{0}, \mathrm{ET}_{0} / \mathrm{RC}, \mathrm{ET}_{0} / \mathrm{CS}_{0}, \Phi \mathrm{R}_{0}, \rho \mathrm{R}_{0}\right)$. These results may indicate the decrease of PSII photochemical efficiency. Simultaneously, PSI reactions remained unchanged and the rate of net photosynthesis increased significantly. This can be connected with the activation of alternative pathways of electron transport. Activation of these pathways leads to the limitation of NADPH synthesis and an increase in ATP synthesis, what enables the plant's effective acclimatization to stress conditions.

Keywords: Dionaea muscipula; photosynthesis; photosynthetic apparatus; UV-A radiation; alternative electron transport pathways

Supplementary Materials: The poster presentation is available online at https:/ /www.mdpi.com/ article/10.3390/IECAG2021-09743/s1. 